\title{
Reseñas
}

Ángel Omar May González, Los primeros años de la posrevolución en Campeche (1921-1929), México, Instituto Mora, 2013, 332 pp.

$\Omega$ omo bien indica el título de este libro, Omar May González nos presenta una historia de los procesos políticos y sociales en Campeche en los nueve años posteriores a la revolución mexicana. Su curiosidad insaciable nos lleva a conocer los detalles de la lucha política en la entidad, cuyo devenir se movió entre los jaloneos de los poderes suprarregionales, encarnados en especial por Felipe Carrillo Puerto, y los intentos del gobierno federal por evitar la autonomía de una región muy alejada del centro del país, de muy difícil acceso por la geografía que la separa del centro.

Se trata de una obra de historia regional que rescata la especificidad del acontecer campechano, apuntalando los hallazgos de la historiografía local: mostrar la especificad de lo regional y no tratar a este estado como un simple apéndice de Yucatán. Así, construye una historia desde la óptica de la localidad, con sus propios tiempos y ritmos, no siempre coincidentes con los nacionales. El texto asemeja un tejido muy apretado, donde se puede apreciar la urdimbre de la historia regional de Campeche, la trama de su relación con la suprarregión peninsular yucateca y la del gobierno federal asentado en la capital de la república. De tal suerte, el libro en cuestión no nos presenta a la historia regional aislada de su contexto nacional y suprarregional, sino que devela los entretelones de estas complejas relaciones, los equilibrios de poder y las alianzas cuidadosamente construidas por sus gobernadores y políticos regionales para aprovecharlos en beneficio de la propia autonomía de su estado y de la prolongación de su dominio.

La fuente del poder regional se asentó en el ejercicio de una política de masas, bautizada como socialista, y en la búsqueda de alianzas con los gobiernos centrales para sacudirse del predominio yucateco. La ambición del autor por trascender el ámbito de lo local, le hizo también comparar los

\section{()ㅜ(1) $\$$}


procesos de Campeche con los acaecidos en otros estados con gobernantes reformistas. Nos presenta una suerte de tipología de los diferentes mandatos locales que florecieron en el país y de sus estilos autonómicos, así como de los juegos que hicieron con el centro para preservar la soberanía y los modos de hacer política en los que aquella se fincaba.

Empero este trabajo no sólo rescata lo regional, lo suprarregional y lo nacional, sino que utiliza categorías para interpretar los procesos campechanos como es, por ejemplo, el "hombre fuerte." Este político más urbano que rural que logró hacerse de y conservar el poder más allá de su propio periodo gubernamental gracias al apoyo de campesinos y trabajadores urbanos de diversos tipos, agremiados en ligas de resistencia, parte de cuyas necesidades eran atendidas para conservar su lealtad, utilizando una retórica que refería como socialistas a las reformas laborales y agrarias. Otro de los conceptos utilizados para comprender la dinámica local es el de diarquía, es decir, la existencia de un político que formalmente detentaba el poder, pero que en realidad lo compartía con aquel que lograba hacerse del control del Partido Socialista Agrario de Campeche (PSAC), quien en ocasiones era el verdadero dirigente de los destinos de la entidad.

El ojo escudriñador con el que May González miró los procesos campechanos lo llevó también a distinguir las dos subregiones que coexistían en el estado y sus particulares posturas políticas, derivadas de actividades económicas absolutamente diferenciadas. Así, la capital estatal, Campeche -con una realidad de trabajadores urbanos dedicados a la pesca, las actividades portuarias y las urbanas, y con una zona de influencia constituida por las comunidades de campesinos mayas en el norte y hacendados plantadores de henequén en la zona colindante con el vecino estado de Yucatán-, constituyó la clientela del PSAC. En cambio, El Carmen, dedicada a la explotación del chicle y las maderas preciosas, que eran extraídas de la selva y exportadas por el propio puerto, vivió en una economía de enclave dominada por empresas extranjeras, con trabajadores aparentemente mejor pagados, y se mantuvo opuesta al predominio del PSAC en la región gracias a sus relaciones directas con el poder federal, derivadas de los impuestos que pagaban las exportaciones.

Una particularidad de Campeche es que imitó el modelo reformista de su vecino Yucatán, pero no tuvo necesidad de realizar reformas agrarias radicales, por una parte, por la poca densidad poblacional del estado $y$, por otra, porque los mayas poseían tierras y casi no sufrieron despojos, ya que la actividad henequenera desarrollada en haciendas con cultivos tipo plan-

\section{(1)(1) $\$$}


tación sólo se dio en una pequeña porción de la entidad. Así, la reforma agraria campechana no necesariamente condujo a confrontaciones con los propietarios de las haciendas, y el Estado tuvo suficientes tierras nacionales para repartir. En cambio, el apoyo a las demandas de los trabajadores sí provocó conflictos con los patrones. Tal como Thomas Benjamin lo ha sugerido, las políticas populistas se iniciaron en la periferia de México y de ahí fueron replicadas por el gobierno central. En este sentido, Campeche no fue la excepción, puso en marcha una política de masas en la cual fincaron su poder los políticos locales. No obstante, a diferencia de lo sucedido en Veracruz con las ligas agrarias o el movimiento obrero, que surgieron de abajo hacia arriba y fueron cooptados por el gobernador Adalberto Tejeda, en Campeche la organización de las ligas de resistencia se impuso de manera vertical de arriba hacia abajo. Fue el Partido Socialista el que organizó las diversas ligas de resistencia y ofreció a los trabajadores y campesinos reformas a cambio de respaldo político. De ahí tal vez derive el talante conservador que rápidamente adquirió la política de los gobernantes "socialistas" campechanos, a diferencia de lo sucedido en otros ámbitos.

La habilidad desplegada por los políticos de la entidad para sacudirse del control yucateco de Carrillo Puerto se puso de manifiesto en ocasión de la rebelión delahuertista de 1923, que tuvo un importante desempeño en la península. Luego del asesinato del líder socialista, los políticos campechanos procuraron forjar lazos con el gobierno nacional y apoyaron la sucesión de Plutarco Elías Calles, la reelección de Obregón en 1928 y respaldaron la fundación del PNR en 1929. De igual manera, respaldaron las decisiones políticas de Calles, cuya influencia creció gracias al vacío dejado por la muerte del Caudillo en julio de 1928, a fin de conseguir que el gobierno de Campeche no quedara supeditado al dominio yucateco, como había sucedido entre 1921 y 1923. Gracias a estas alianzas exitosas con los políticos del centro, los campechanos que dominaban el PSAC lograron imponer a sus propios candidatos en la gubernatura y en los Congresos local y federal.

Se trata de una realidad abigarrada, difícil de enmarcar en las categorías derivadas del estudio de las democracias occidentales. May Martínez utilizó su imaginación para crear explicaciones que superen lo meramente factual y logren dilucidar la dinámica de lo acaecido, no solamente con la utilización de categorías por él definidas, sino con la presentación de procesos electorales en los que los líderes manipulaban a los votantes gracias a una estructura partidista asentada en ligas de resistencia que recibían los favores directamente de los gobernadores o merced al poder de los presidentes del

\section{()(1) $\$$}


PSAC. Así, la legitimidad política nacía de las relaciones clientelares que sostenían los políticos con los sectores populares, y las elecciones eran simples procesos plebiscitarios que servían para asegurar el dominio de los puestos de elección popular por parte de los políticos en turno.

Omar May González presenta en Los primeros años de la posrevolución en Campeche (1921-1929), la historia de otro "laboratorio de la revolución mexicana" que viene a completar el complejo rompecabezas de la política estatal y nacional de la tercera y cuarta décadas del siglo xx y, en este sentido, es una contribución importante a la historiografía, bautizada como revisionista por Alan Knight, que profundiza en el conocimiento de los procesos locales que integran la historia nacional.

Este libro se fundamenta en una investigación profunda en archivos nacionales como el General de la Nación y el Fideicomiso Archivos Plutarco Elías Calles y Fernando Torreblanca y en locales, como el Archivo General del Estado de Campeche. Asimismo abrevó en una amplia investigación hemerográfica en periódicos nacionales y estatales de Campeche y Yucatán. Todo esto combinado con una amplia bibliografía especializada en el México de la tercera y la cuarta décadas del siglo xx.

El texto se divide en siete capítulos dedicados a los distintos periodos de gobierno que se desarrollaron desde la etapa carrancista hasta la fundación del Partido Nacional Revolucionario en 1929, cuando el PSAC, esa maquinaria local creada en el estado peninsular, se integró las filas del flamante partido oficial nacional. También contiene varios mapas de gran utilidad y un anexo, donde se pergeñan biografías de los personajes que actúan en esta trama.

En la introducción, el autor discute los principales conceptos teóricos que utilizará para explicar el actuar de los políticos campechanos en las décadas de 1920 y 1930. El primer capítulo se dedica a los cambios que trajo la revolución mexicana en Campeche, desde el gobierno de Francisco I. Madero hasta el de Venustiano Carranza. El siguiente se aboca a la formación del PSAC y a las diferentes luchas de los políticos locales por hacerse del control de la entidad. El tercero analiza el gobierno de Ramón Félix Flores y la creación de bases de poder propias en las ligas de resistencia. El capítulo cuarto aborda la rebelión delahuertista y la manera en que los políticos locales aprovecharon el vacío de poder que dejó la muerte de Felipe Carrillo Puerto en la región, para aumentar su control sobre el estado. El capítulo que le sigue presenta la crisis que surgió entre los políticos que se autodenominaban socialistas a causa de la lucha encarnizada por el poder durante los primeros

\section{()(1) $(9$}


años del gobierno de Plutarco Elías Calles. El capítulo sexto explica la construcción de bases de poder propias de Ángel Castillo Lanz, las reformas que realizó y cómo fue su relación con el centro. Por último, la parte final se refiere a la sucesión del gobierno local y la inserción del PSAC al recién fundado Partido Nacional Revolucionario en 1929.

María del Carmen Collado Instituto de Investigaciones Dr. José María Luis Mora, México ccollado@institutomora.edu.mx

Juan José Saldaña, Las revoluciones politicas y la ciencia en México, México, CONACYT, 2010, 2 vols., ISBN de la obra completa: 978-607-95194-7-6.

$\mathrm{H}$ an pasado cuatro años desde la celebración del bicentenario y centenario de las revoluciones de México, lapso que nos permite ver con un ojo menos saturado por los oropeles la producción historiográfica de aquel momento para reconocer las aportaciones heurísticas que algunas obras entonces publicadas hicieron al conocimiento histórico en sus diferentes temáticas.

En 2010 el Consejo Nacional de Ciencia y Tecnología (ConACyT) publicó en dos volúmenes la obra del historiador de la ciencia Juan José Saldaña, titulada Las revoluciones políticas y la ciencia en México. Se trata de un libro que nos muestra simultáneamente el papel que la ciencia moderna desempeñó en la formación del Estado mexicano y las acciones emprendidas por este para la institucionalización de la actividad científica en la medida en que fue adquiriendo la capacidad técnico-política para ello, desde las expresiones autonómicas de los criollos novohispanos al concluir el siglo XVIII hasta la revolución constitucionalista de la segunda década del siglo xx.

En la historiografía mexicana los componentes epistémicos de los procesos revolucionarios han ocupado un sitio marginal. Esta situación obedece a una serie de presupuestos que apuntan a la falta de incidencia o inexistencia de dichos componentes tanto en la revolución de independencia de 1810 como en la mexicana de un siglo después. En Las revoluciones políticas y la ciencia en México Saldaña recurrió al empleo de conceptos historiográficamente innovadores para mostrar que dichos presupuestos son insuficientes para explicar la complejidad de ambos procesos históricos.

Saldaña acuñó el concepto "ciencia en la acción y para la acción" para referirse a la ciencia (incluyendo la tecnología) gestada en los procesos revolu-

\section{()(1) $(3$}

